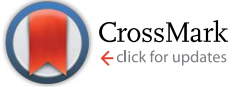

Cite this: RSC Adv., 2017, 7, 10718

Received 11th November 2016

Accepted 27th January 2017

DOI: $10.1039 /$ c6ra26665g

rsc.li/rsc-advances

\section{Synthesis and characterization of metallo- supramolecular polymers from thiophene-based unimers bearing pybox ligands $\uparrow$}

\author{
Sviatoslav Hladysh, ${ }^{\text {a }}$ Daniela Václavková, ${ }^{\mathrm{b}}$ David Vrbata, ${ }^{a}$ Dmitrij Bondarev, ${ }^{\text {bc }}$ \\ David Havlíček, ${ }^{d}$ Jan Svoboda, ${ }^{e}$ Jiři Zedník $^{a}$ and Jiři Vohlídal ${ }^{a}$
}

\begin{abstract}
A series of novel metallo-supramolecular polymers was successfully prepared, based on 2,6-bis(2oxazolinyl)pyridine building blocks consisting of pyridine flanked by two oxazoline rings as a tridentate binding site bridged with thiophene, bithiophene and thienothiophene as a linker, beginning from a cheap and commercially available 1,4-dihydro-4-oxo-2,6-pyridinedicarboxylic (chelidamic) acid. Metallosupramolecular polymers were obtained and spectroscopically characterized upon treatment of the synthesized building blocks, also known as unimers, with the following metal ions: $\mathrm{Fe}^{2+}, \mathrm{Zn}^{2+}, \mathrm{Ni}^{2+}, \mathrm{Cu}^{2+}$. During the self-assembly process of the prepared unimers with a $\mathrm{Cu}^{2+}$ ion coupler, UV/vis investigation showed the highest shift of absorption maxima to lower energies, contrary to the $\mathrm{Fe}^{2+}$ ion couplers where the lowest value of shift was detected, compared to the free unimer. Upon the complexation of the $\mathrm{Fe}^{2+}$ ion coupler with selected unimers, the appearance was observed of new absorption bands around $600 \mathrm{~nm}$ ascribable to metal-to-ligand charge-transfer transitions. The luminescence study of the complexation of the synthesized unimers with $\mathrm{Zn}^{2+}$ exhibited a high fluorescence increase with an increase of metal ion concentration. Adversely, all of the other metals only showed fluorescence quenching.
\end{abstract}

\section{Introduction}

Supramolecular materials have attracted the attention of many researches during the past decades. ${ }^{\mathbf{1 , 2}}$ An important subclass of these materials is represented by metallo-supramolecular polymers (MSPs). ${ }^{3}$ They are typically built from low-molar-mass (multidentate) organic molecules (denoted as unimers (U) analogous to the monomer unit in the classic polymer or micelle building units) that are self-assembled into larger arrays or chains by non-covalent (labile) interactions typical of coordination bonds with metal ion couplers (ICs). This lability of the coordination bonds gives the resulting materials a dynamic nature and, consequently, these materials belong to the family of materials called dynamers (a term introduced by Nobel Prize

\footnotetext{
${ }^{a}$ Department of Physical and Macromolecular Chemistry, Faculty of Science, Charles University in Prague, Hlavova 8, CZ-12840 Prague 2, Czech Republic. E-mail: sviatoslavhladysh@gmail.com

${ }^{b}$ Tomas Bata University in Zlin, Faculty of Technology, Department of Polymer Engineering, Vavrečkova 275, CZ-762 72 Zlin, Czech Republic

'Polymer Institute, Slovak Academy of Sciences, Dubravska cesta 9, 84541 Bratislava, Slovakia

${ }^{d}$ Department of Inorganic Chemistry, Faculty of Science, Charles University in Prague, Hlavova 8, CZ-12840 Prague 2, Czech Republic

${ }^{e}$ Institute of Macromolecular Chemistry AS CR, v.v.i, Heyrovsky Sq. 2, 16206, Prague 6, Czech Republic
}

$\dagger$ Electronic supplementary information (ESI) available. See DOI: 10.1039/c6ra26665g laureate Jean-Marie Lehn). ${ }^{4}$ Labile bonding introduces interesting new properties and allows the possibility of precise system tailoring by the structure of unimers and character and

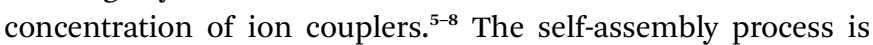
achieved by introducing the ion coupler into the unimer solution, or vice versa. This process proceeds by the formation of coordination bonds (complexation) between the Us and ICs, leading to the formation of MSPs by the self-assembly process. The term complexation is also used for the formation of "model" complexes that are also presented in this contribution. Therefore, complexation is a general tool for the preparation of either MSPs by the self-assembly process or simple metal-ligand complexes prepared by coordination with standard ligand possessing only one chelating binding site. Large self-assemblies are formed in the case of multifunctional Us possessing at least two chelating binding sites. Most MSPs are typically processed in the solid state as thin films. There are two aspects of MSP stability in solution. The first is represented by the thermodynamic stability constant of the coordination sites of the $\mathrm{U}$ molecules and selected metal ICs. The second aspect is related to the kinetics of the labile coordination bonding, characterized by the exchange rate of the free unimer and in the supramolecular assembly. The kinetic aspect of equilibrium in solution is denoted as a constitutional dynamic in further text.9,10

The application potential of MSPs is broad across various fields: MSPs with low $T_{\mathrm{g}}$ are utilized in self-healing applications ${ }^{11,12}$ as well as various responsive systems, ${ }^{13-16}$ including 
MSPs that contain totally conjugated Us exploited in optoelectronic devices (light-emitting diodes, photovoltaic cells) ${ }^{17-20}$ or biomedical applications. ${ }^{21}$ Despite extensive work in our laboratory with tridentate $2,2^{\prime}: 6^{\prime} 2^{\prime \prime}$-terpyridine-4-yl units, ${ }^{22-27}$ the decision to synthesize ditopic unimers with another tridentate ligand - 2,6-bis(oxazolyl)pyridine (pybox) - has been taken into account. The main reasons behind this decision were as follows: (i) oxazoline complexes have a large application potential in microelectronics and also as catalytic systems (especially Ru-based pybox derivatives); ${ }^{28-32}$ (ii) pybox based ligands allow an easy derivatization through attaching substituents at the 4-position of the pyridine rings (in this case, optical isomerism is introduced into the pybox motif, allowing further tailoring of the prepared systems); (iii) pybox derivatives exhibit much better solubility in organic solvents, which is an important parameter in MSP processing. ${ }^{33}$ Therefore, all these abovementioned potential advantages of the bis(oxazolines), in combination with the thiophene based central blocks, bring their own benefits such as the possibility of band gap tuning, high absorption coefficients, charge transport properties, etc. The tridentate ditopic pybox ligand has been partly described by A. Duerrbeck. ${ }^{34}$ But, to the best of our knowledge, the synthesis, characterization and optical properties of $\alpha, \omega$-bis(2,6bis(oxazoline-2-yl)pyridin-4-yl)thiophene (P-Th), $\alpha, \omega$-bis(2,6bis(oxazoline-2-yl)pyridin-4-yl)bithiophene (P-Bt) and $\alpha, \omega$ bis(2,6-bis(oxazoline-2-yl)pyridin-4-yl)thieno[3,2- $b]$ thiophene (P-Te) are new. Moreover, the process of self-assembly of the prepared unimers into MSPs by means of complexation with the selected model ion couplers, $\mathrm{Fe}^{2+}, \mathrm{Zn}^{2+}, \mathrm{Ni}^{2+}, \mathrm{Cu}^{2+}$, performed like a detailed properties survey, is also new. $\mathrm{Cu}^{2+}$ radioisotopes can coordinate suitable ligands and such a method opens applications in diagnostic and therapeutic areas. ${ }^{35}$ The $\mathrm{Zn}^{2+}$ complexes are used as sensitizers in solar cells. ${ }^{36}$ Both $\mathrm{Ni}^{2+}$ and $\mathrm{Fe}^{2+}$ ions could catalyze various types of chemical reactions. The $\mathrm{Ni}^{2+}$ complexes became attractive catalysts for the reduction of alkynes, olefins, ketones and aldehydes in high yields. ${ }^{37-39}$ The $\mathrm{Fe}^{2+}$ complexes are used for various organic transformations, such as olefin polymerization, ${ }^{40}$ Mukaiyama-aldol reaction, ${ }^{41}$ etc. These observations of d-transition metals make the selfassembly process with synthesized unimers a highly attractive research field. The presented investigations introduce novel information concerning the coordination of unimers and the consequent corresponding MSP formation. Thiophene, bithiophene and thieno[3,2- $b]$ thiophene linkers between pybox groups were chosen as competing units to phenyl linkers that were studied in the above mentioned work. ${ }^{34}$ The incorporation of these units can positively influence the photophysical and electrochemical properties due to a lower stiffness and a higher conjugation extent of the pybox based unimers used for MSP preparation. $^{42}$

\section{Results and discussion}

\section{Synthesis}

The synthesis pathway to the unimers studied is depicted in the ESI as Scheme S1. $\dagger$ The precursor (7) 4-bromo-2,6-bis(4,5dihydro-2-oxazolyl)-pyridine was synthesized from a cheap chelidamic acid in high yield $(82 \%)$ by a 6 -step procedure applying a simple type of chemical reaction. The compound successfully obtained (7) was further transformed through a Stille reaction ${ }^{43}$ into appropriate unimers using 2,5-bis(trimethylstannyl)thiophene, $\quad 5,5^{\prime}$-bis(trimethylstannyl)-2,2' bithiophene or 2,5-bis(trimethylstannyl)-thieno[3,2- $b]$ thiophene as the coupling reagents. As compound (7) possesses a reactive bromide in the para position of the pyridine moiety, it allows the introduction of various substituents into the molecule. Based on this fact, the Pybox-Th ligand (see Scheme 1 and ESI $\dagger$ ) was synthesized using a Suzuki coupling reaction. The prepared unimers and ligand were characterized by common spectroscopic methods.

\section{UV/vis spectroscopy analysis}

Complexation study of Pybox-Th ligand. The UV/vis study of the prepared unimers and spectral changes upon the addition of selected ICs is one of the most important parts of the present contribution. As a first step, a complexation study of the PyboxTh ligand upon titration with the $\mathrm{Fe}^{2+}$ and $\mathrm{Zn}^{2+}$ ICs was done. The experiment was performed in a mixed solvent of chloroform/methanol (1/1 by volume). The titration course, reflected by changes in the absorption spectra upon Pybox-Th ligand titration with $\mathrm{Zn}^{2+}$ and $\mathrm{Fe}^{2+}$, is shown in Fig. S1. $\dagger$

Upon the IC addition to the ligand solution the absorption maxima shifted to lower energies. The metal-to-ligand charge transfer transition (MLCT) at $580 \mathrm{~nm}$ was observed in the case of the iron salt. ${ }^{\mathbf{4 4}, 45}$ Isosbestic points are present in both titrations with the mentioned ICs, indicating the presence of a coordinated (ligand-IC-ligand) symmetric form, referred to in the literature as a "butterfly dimer", ${ }^{46}$ and free ligand in solution. The equilibrium character of the mixture and an approximate character of the described model must always be kept in mind. All the possible compounds (IC, free unimer, ligand-IC and ligand-IC-ligand) are always present in the reaction mixture, dependent upon the thermodynamic stability constant of each species.

Properties of unimers. The synthesized unimers (P-Th, P-Bt, P-Te) consist of two tridentate coordinating (binding) site (oxazoline-pyridine) moiety bridged by the thiophene based linkers. Optical properties are strongly dependent on the thiophene derivative linker used in the unimer's structure. Absorption maxima $\left(\lambda_{\mathrm{A}}\right)$ of the prepared unimers, denoted as $\mathrm{U}$, are summarized in Table 1 . Whole UV/vis spectra of the unimers are presented in the ESI as Fig. S2. $\dagger$ The wavelengths of absorption maxima exhibit a decrease to lower energies in the following order: P-Th $>$ P-Te $>$ P-Bt. The lowest energy absorption maximum was observed for the unimer P-Bt. This observation is caused by the highest conjugation, i.e. more pronounced $\pi-\pi$ interactions of the aromatic parts of the mentioned unimer. The difference at absorption maxima position $\left(\lambda_{\mathrm{A}}\right)$ between P-Th and P-Bt is $50 \mathrm{~nm}$ (see Fig. S2 $\dagger$ ). The molar absorption coefficients $(\varepsilon)$ are summarized in Table 1. The highest $\varepsilon$ was observed for the P-Te unimer. On the other hand, P-Th showed the lowest $\varepsilon$ value. Stokes shifts between the 

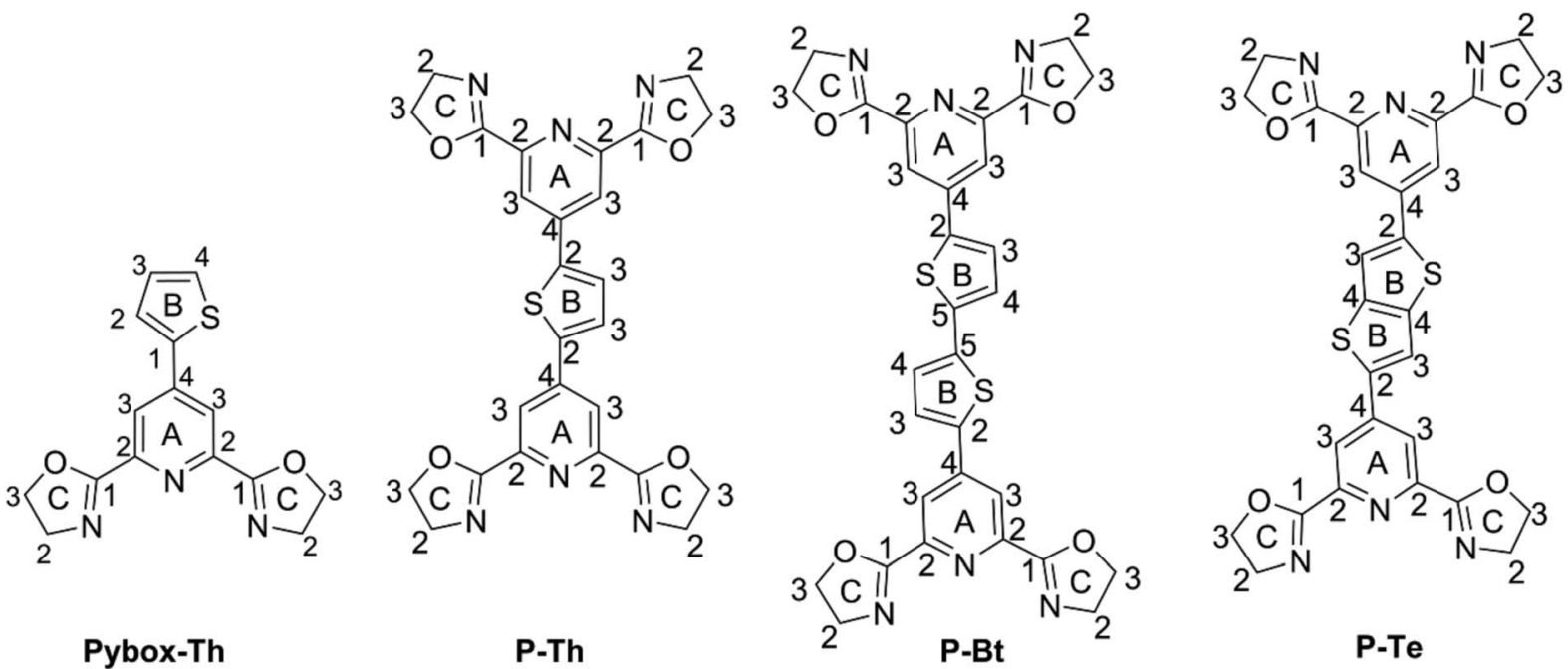

Scheme 1 Synthesized unimers $(U)$ and ligands with formal group numbering for NMR.

absorption and emission bands showed a tendency to increase with the increase of band gap energy.

Self-assembly of unimers to MSPs in solution. A UV/vis spectroscopy study of the prepared unimers upon their complexation into MSPs, using the various metal ion couplers $\mathrm{Fe}^{2+}, \mathrm{Zn}^{2+}, \mathrm{Ni}^{2+}$ and $\mathrm{Cu}^{2+}$ was performed. A mixed solvent of chloroform/methanol ( $1 / 1$ by volume) was used to dissolve the unimers and metal ions. This solvent system was found to be the most suitable for dissolving all the components during the MSP preparation. Moreover, this solvent mixture was chosen as the simplest representative of polar and non-polar solvents for forming a positive azeotrope. Standard dipolar aprotic solvents, such as pure dimethyl sulfoxide (DMSO) or $\mathrm{N}, \mathrm{N}$-dimethylformamide (DMF), were not used because of their inhibition of supramolecular system formation in the above-mentioned solvents at the concentration $\left(2 \times 10^{-4} \mathrm{M}\right)$ used in the UV/vis study. But an increase of concentration in DMSO of two orders up to $2 \times 10^{-2} \mathrm{M}$ provides the formation of MSPs, as was also observed by an NMR titration study. Therefore, it is obvious that the thermodynamic solvent quality strongly influences the stability constants of species formed in the mixture. ${ }^{47}$

A set of solutions of constant unimer's concentration $(2 \times$ $\left.10^{-4} \mathrm{M}\right)$ and metal ions $\left(2 \times 10^{-2} \mathrm{M}\right)$ was prepared as the chosen mixed solvent (chloroform/methanol) for the UV/vis titration study. By the method of a stepwise increase of the ion coupler to unimer ratio, MSPs systems were obtained that were subsequently studied spectroscopically. The $[\mathrm{IC}] /[\mathrm{U}]$ ratio is denoted as $r$ in further text.

The results are summarized in Fig. 1 for P-Bt, and the rest of the titration results of P-Th and P-Te with various ICs are shown in Fig. S3 and S4 in the ESI. $\uparrow$ The optical parameters of all the unimers and metallo-supramolecular polymers are shown in Table 1.

The self-assembly process of unimers with ICs is accompanied by the appearance of new absorption bands. A UV/vis study of this process allows us to track the formation of MSPs. The absorption spectra obtained for studied systems can be analyzed by the three stages of assembly using different values of $r$. The first stage covers ratios of $r$ from 0 to 0.5 and shows: (i) the negligible changes of band shape, (ii) the appearance of new absorption bands and (iii) the formation of isosbestic points (IP) indicating the transformation of free $\mathrm{U}$ species into other defined forms in solution. The stoichiometry hints that the new species could be the dimer (U-(IC)-U), analogous to the abovementioned "butterfly dimer".46 The second stage of the assembly process, from $r 0.6$ to 1 , shows the shift of newly

Table 1 Optical data of unimers $(\mathrm{U})$ with different metal ions: $\lambda_{\mathrm{A}}$ wavelength of absorption maximum (nm); $\varepsilon_{\max }$ molar absorption coefficient in absorption maxima $\left(\mathrm{dm}^{3} \mathrm{~mol}^{-1} \mathrm{~cm}^{-1}\right) ; \lambda_{\mathrm{e}}$ absorption edge $(\mathrm{nm}) ; \lambda_{\mathrm{F}}$ wavelength of emission maximum (nm); $S$ Stokes shift $\left(\mathrm{cm}{ }^{-1}\right), r$ unimer to metal ion ratio

\begin{tabular}{|c|c|c|c|c|c|c|c|c|c|c|c|c|c|c|c|c|}
\hline \multirow[b]{2}{*}{ IC } & \multicolumn{6}{|c|}{ P-Th } & \multicolumn{5}{|l|}{ P-Bt } & \multicolumn{5}{|l|}{ P-Te } \\
\hline & $r$ & $\lambda_{\mathrm{A}} \mathrm{nm}$ & $\lambda_{\mathrm{e}} \mathrm{nm}$ & $\varepsilon_{\max }$ & $\lambda_{\mathrm{F}} \mathrm{nm}$ & $S \mathrm{~cm}^{-1}$ & $\lambda_{\mathrm{A}} \mathrm{nm}$ & $\lambda_{\mathrm{e}} \mathrm{nm}$ & $\varepsilon_{\max }$ & $\lambda_{\mathrm{F}} \mathrm{nm}$ & $S \mathrm{~cm}^{-1}$ & $\lambda_{\mathrm{A}} \mathrm{nm}$ & $\lambda_{\mathrm{e}} \mathrm{nm}$ & $\varepsilon_{\max }$ & $\lambda_{\mathrm{F}} \mathrm{nm}$ & $S \mathrm{~cm}^{-1}$ \\
\hline $\mathrm{U}$ & 0 & 350 & 491 & 8.9 & 404 & 3820 & 400 & 526 & 12.6 & 532 & 6210 & 373 & 516 & 15.3 & 510 & 7209 \\
\hline $\mathrm{Fe}^{2+}$ & 1 & 371 & 698 & 7.2 & 408 & 2445 & 411 & 687 & 10.5 & 480 & 3490 & 398 & 702 & 10.9 & 440 & 2390 \\
\hline $\mathrm{Zn}^{2+}$ & 1 & 380 & 516 & 8.7 & 434 & 3270 & 445 & 625 & 13.3 & 542 & 4020 & 422 & 566 & 14.6 & 483 & 2990 \\
\hline $\mathrm{Ni}^{2+}$ & 1 & 375 & 523 & 10.6 & 409 & 2210 & 449 & 594 & 15.6 & 496 & 2110 & 427 & 567 & 17.9 & 465 & 1910 \\
\hline $\mathrm{Cu}^{2+}$ & 1 & 388 & 538 & 10.2 & 421 & 2020 & 457 & 632 & 12.8 & 501 & 1920 & 433 & 583 & 14.9 & 474 & 1990 \\
\hline
\end{tabular}



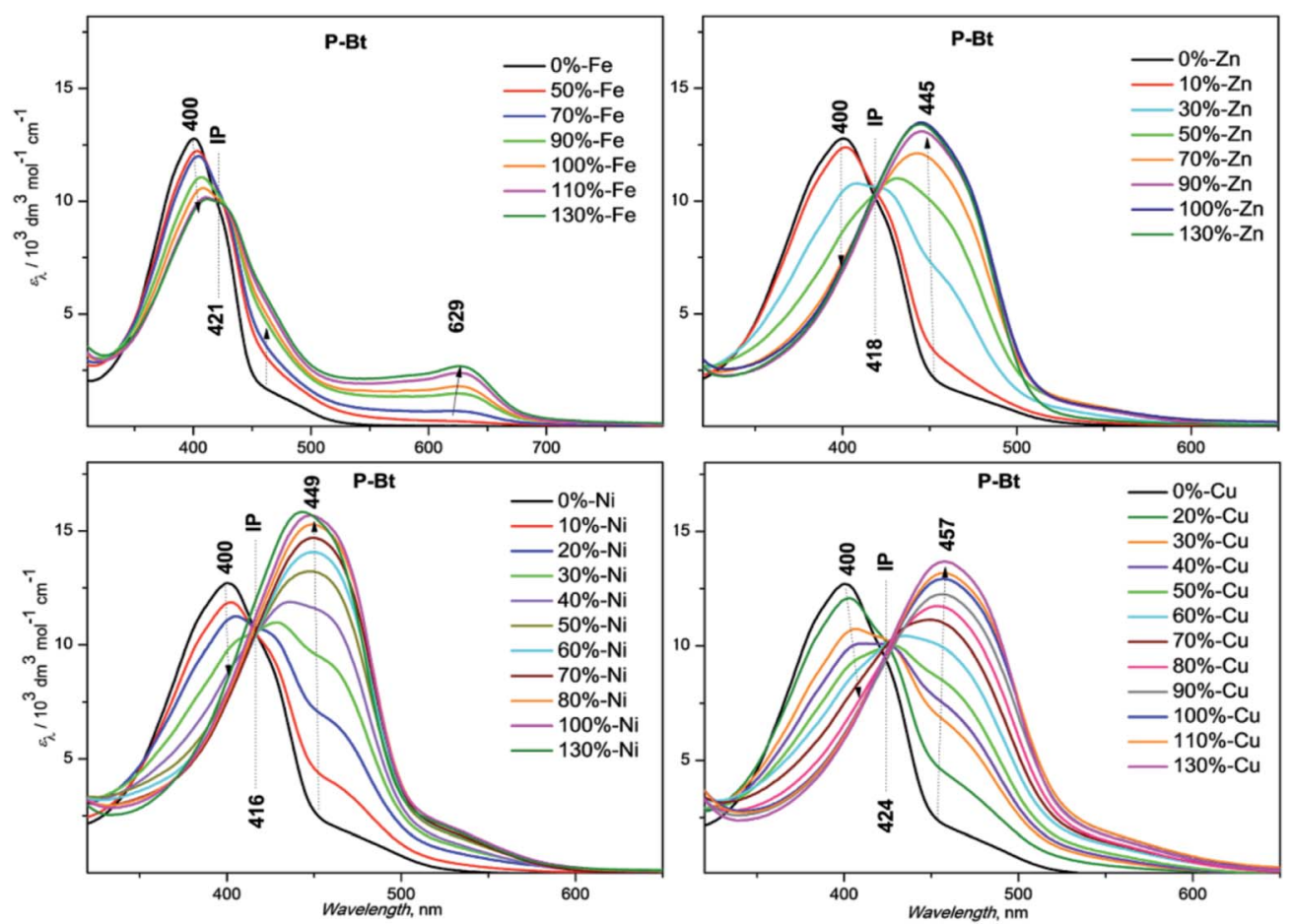

Fig. 1 UV/vis titration spectra of P-Bt $\left(2 \times 10^{-4} \mathrm{M}\right.$, based on the monomer unit), with ion couplers $\left(2 \times 10^{-2} \mathrm{M}\right)$.

formed absorption bands to lower energies accompanied with an increase in the molar absorption coefficient $(\varepsilon)$ (except $\mathrm{Fe}^{2+}$ IC, which shows a decrease of $\varepsilon$ ). The last stage (where $r>1$ ) does not show significant changes in the absorption spectra and can be considered as a depolymerization process of the MSPs, where the pybox end moiety is end-capped by IC coordinated only from one side. According to the UV/vis analysis of all stages of the self-assembly process, MSPs gain the maximum length at a ratio $(r)$ of about 1 . As already mentioned above, the studied system is dynamic and the described model serves as a rough description of the presumed behavior. It is obvious that the various chemical species present in the mixture depends upon the stability constants of each compound. Consequently, at $r=$ 0.5 (as an example) "butterfly dimers" are present in the mixture as well as longer polymeric fragments, so free IC and $\mathrm{U}$ could be expected in the reaction mixture. It can be concluded that, at selected overall concentrations of the components in the system, the model fits well the observed spectral behavior during its titration course. In summary, the polymerization degree is not dependent only on the values of $r$, but is also a function of the overall concentration and solvents used.

Absorption maximal positions differ in their dependence on the metal ion coupler used for the MSP preparation. The highest shifts to longer wavelengths (about $50 \mathrm{~nm}$ ) compared to the corresponding free $\mathrm{U}$ is observed in the case of $\mathrm{Cu}^{2+}$ (see ESI, Fig. S5 $\dagger$ ). Maximal absorption shifts to longer wavelengths were detected during the titration experiment (only $20 \mathrm{~nm}$ ) for $\mathrm{Fe}^{2+}$ at $r=1$. But this MSP displays new absorption bands at around $630 \mathrm{~nm}$ that are attributed to the metal-to-ligand charge transfer transition (MLCT) (see Fig. 1, S3 and S4 in the ESI $\dagger$ ).
Additionally, the influence of $r$ on the absorption maximal position of newly formed bands corresponding to MSP formation has been characterized by means of graphical dependence (see ESI, $\uparrow$ Fig. S6†). In all the cases, we observed a similar trend, with significant shifts to lower energies after the addition of the first portion of IC $(r=0.3)$. The stepwise increase of IC concentration leads to further shifts of absorption band positions to lower energies. The maximal absorption edges of MSPs with various ICs at $r=1$ are summarized in Table 1 . The $\mathrm{Ni}^{2+}$ ion coupler showed the lowest energy maximum position at $r=0.5$. Further addition of the $\mathrm{Ni}^{2+}$ IC has practically no influence on the absorption maximum position. This observation indicates that the thermodynamically preferred motif in the case of the $\mathrm{Ni}^{2+}$ IC is the "butterfly dimer" U-IC-U. Further addition of the $\mathrm{Ni}^{2+}$ IC probably leads to the prolongation of the MSP chains formed. The rest of the ICs, $\mathrm{Fe}^{2+}, \mathrm{Zn}^{2+}, \mathrm{Cu}^{2+}$, exhibit a gradual shift of absorption bands to lower energies $r$ (from 0.1 up to 1 ). In these cases, the IC-U moiety was formed in the first step (the ion coupler is coordinated only by one tridentate pybox moiety). The next step is represented by the dimer formation of a U-IC-U type, followed by MSP chain formation with increasing $r$. The longest MSP chains are expected at $r$ equals unity in all the studied systems (see Table 1 above, a summary of all the basic optical properties). The further addition of IC ions probably leads to the shortening of MSP chains and to the formation of MSPs end-capped by an IC moiety on the chain-ends. All the systems are of a dynamic nature. It can be presumed that chemical relaxation (rate of reaching the equilibrium) is different in dependence on the $\mathrm{U}$ and IC character in each experiment. 1 day $(24 \mathrm{~h})$ was found to be sufficient for the 


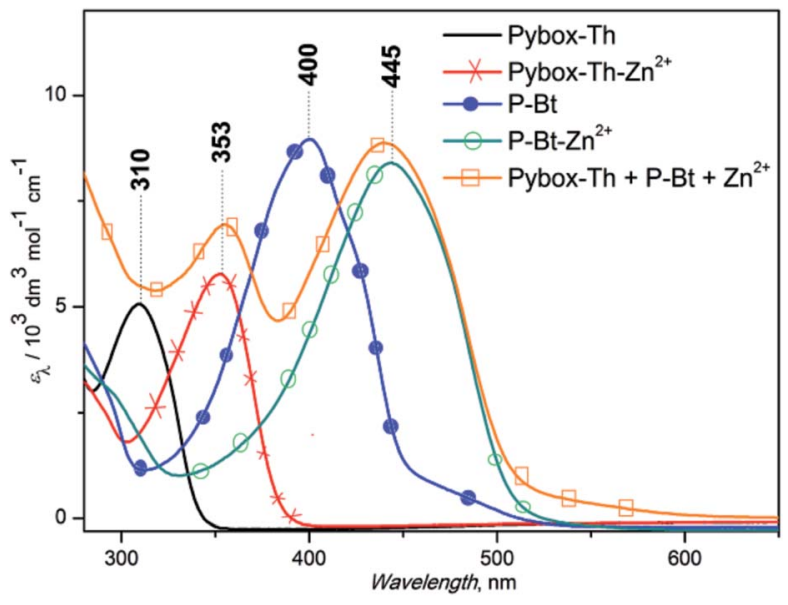

Fig. 2 Absorption spectra of P-Bt end-capping experiment.

equilibration of all the studied systems. It is presumed that $24 \mathrm{~h}$ is a sufficient time for chemical relaxation of all the studied systems and all the components are in an inner equilibrium. But it is worth mentioning that even after $24 \mathrm{~h}$, supramolecular systems are still of a dynamic nature and the introduction of additional portions of IC or U leads to re-equilibration. This process is more precisely described below as an end-capping experiment.

The observed behavior indicates that a change in the overall concentrations of all the components in the studied system leads to immediate re-equilibration of the studied system in the solution. Unfortunately, this fact disallows a GPC/SEC study of the prepared MSPs. The injection of the studied mixture into GPC columns leads to several orders of dilution in the studied materials. Chemical relaxation (rate of reaching equilibrium) appears quickly enough to decompose the formed MSPs. Only free unimer is observed at the end of the GPC path in all cases. The ion coupler remains bound on the styragel-based GPC columns. Strong chelating reagents, like bipyridine or EDTA, must be used to release the metal ions from the column.

The end-capping experiment of the end-groups of MSP was performed based on P-Bt unimer and $\mathrm{Zn}^{2+}$ ion coupler $(r=1)$ by the addition of a Pybox-Th ligand. The addition of the Pybox-Th ligand to the solution of MSP leads to the appearance of a new absorption band with a maximum at $353 \mathrm{~nm}$ and a shoulder at $550 \mathrm{~nm}$ (yellow line, Fig. 2). The complexation study of the Pybox-Th ligand with the $\mathrm{Zn}^{2+}$ IC showed shifts to a lower energy with an absorption maximum at $353 \mathrm{~nm}$. The fact that the $\mathrm{Zn}^{2+}$
ICs at the chain-ends of the MSP are end-capped by Pybox-Th ligands confirms the dynamic character of the studied MSPs in solution.

Study of solid state unimers and corresponding MSPs. The absorption spectra of P-Th, P-Bt, P-Te and MSPs based on the above mentioned unimers with $\mathrm{Zn}^{2+}$ IC in solid thin films were measured and the basic optical properties are collected in Table 2. The complete appearance of the UV/vis spectra in a solid thin film are presented in the ESI as Fig. S7. $\dagger$ The absorption maxima of P-Th in the film and the solution are nearly at the same positions. This fact indicates a similar conformation of P-Th in both solution and solid state. UV/vis spectra of P-Bt and P-Te in the thin films are more red-shifted than those in solutions. The difference in the absorption maxima between the two states (solid and solution) for P-Bt is $14 \mathrm{~nm}$ and for P-Te it is around $5 \mathrm{~nm}$, indicating that the bithiophene linker is more rigid than the thienothiophene in the P-Te unimer. The minor difference between the absorption maxima position in both states confirms a similar conformation and flexibility in solution and solid state.

The solid-state structure of unimers and their MSPs with the $\mathrm{Cu}^{2+}$ IC was investigated by powder X-ray diffraction (XRD), allowing insight concerning the crystallinity of the abovementioned materials. $\mathrm{Cu}^{2+}$ was chosen as the best IC leading to the highest shifts of absorption maximum to lower energies ascribable to the formed MSPs (see Table 1). The narrow width of the peaks and the presence of higher order reflections at low angles of P-Bt and P-Te samples in the XRD patterns indicated the high degree of crystallinity of the unimers studied. XRD patterns of P-Bt showed an intense and sharp first-order reflection at a $d$ spacing of $5.7 \AA$ in the $2 \theta$ range of $16^{\circ}$ (see Fig. 3, and S8 in the ESI $\dagger$ ) corresponding to X-ray diffraction patterns of P-Th, P-Te and their $\mathrm{Cu}^{2+}$ based MSPs.

The second most intense peak occurred at $2 \theta=26^{\circ}$ and corresponded to a $d$ spacing of $3.5 \AA$. Additionally, the relatively intense presence of reflections with a low intensity but high sharpness in the $2 \theta$ range of $15-25^{\circ}$ was observed for the P-Bt unimer. This detection points to a high degree of crystallinity together with a high rigidity of the conjugated bithiophene linker, which was also confirmed by a UV/vis study of solid thin films. The XRD pattern of P-Te showed the two sharpest peaks at $2 \theta=9^{\circ}$ and $28^{\circ}$, corresponding to a $d$ spacing of $10 \AA$ and $3.3 \AA$, respectively. As a result, the packaging of P-Te is the same as for P-Bt unimer. Adversely, the P-Th unimer showed a negligible degree of crystallinity. Such observations, together with UV/vis solid-state results for the P-Th sample, are caused by less

Table 2 Data of the fluorescence quantum yields $\left(\phi_{\mathrm{F}}, \%\right)$ and emission maxima $\left(\lambda_{\mathrm{F}}\right) \mathrm{nm}$ of unimers and their Zn-containing MSPs in both states (solution and solid)

\begin{tabular}{|c|c|c|c|c|c|c|c|c|c|c|c|c|}
\hline State & \multicolumn{6}{|c|}{ Unimer } & \multicolumn{6}{|l|}{ MSP } \\
\hline Solution & 12.8 & 404 & 7.3 & 455 & 14.3 & 420 & 22.2 & 434 & 34.2 & 542 & 17.4 & 483 \\
\hline Film & 1.57 & 580 & 1.17 & 603 & 1.45 & 554 & 2.02 & 614 & 1.99 & 635 & 1.51 & 618 \\
\hline
\end{tabular}




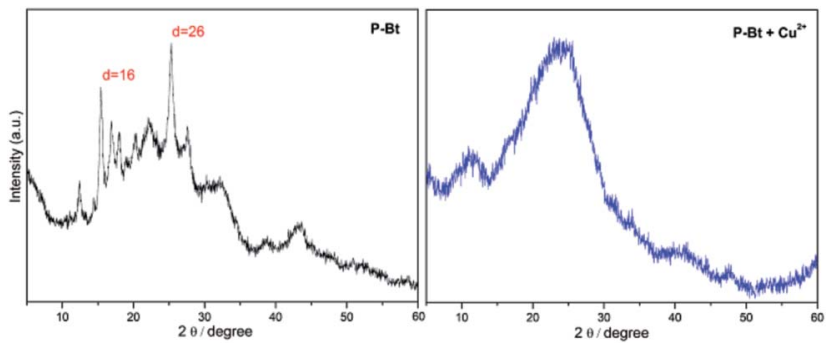

Fig. 3 X-ray diffraction pattern of $\mathrm{P}-\mathrm{Bt}$ and its $\mathrm{Cu}^{2+}$ based MSP. The molar ratio between the unimer and $\mathrm{Cu}^{2+}$ is $(1: 1)$.

ordered configurations. The self-assembled systems, or MSPs, were also included in the XRD analysis. Their diffraction patterns demonstrated a lack of high order reflections in all the unimer based supramolecular systems. Only the broadening of peaks was observed, indicating the amorphous character of the synthesized (MSP)s.

X-ray photoelectron spectroscopy analysis (XPS) was used for the analysis of both free unimers and their MSPs with $\mathrm{Cu}^{2+}$ IC. This method was used as an additional tool for the analysis of MSP formations and also for establishing the correct coordination center of the oxazoline moiety ( $\mathrm{N}$ or $\mathrm{O}$ atom). The N1s and O1s XPS spectra of the P-Bt unimer and corresponding $\mathrm{Cu}^{2+}$ based MSP are shown in Fig. 4. For all the unimers studied (P-Th, P-Bt and P-Te), a change of position of the peaks in the N1s spectra to a higher binding energy (1.1-2 eV) was observed. This is caused by the electron withdrawing capacity of $\mathrm{Cu}^{2+}$ ions, which remove more valence electrons of the nitrogen atoms in
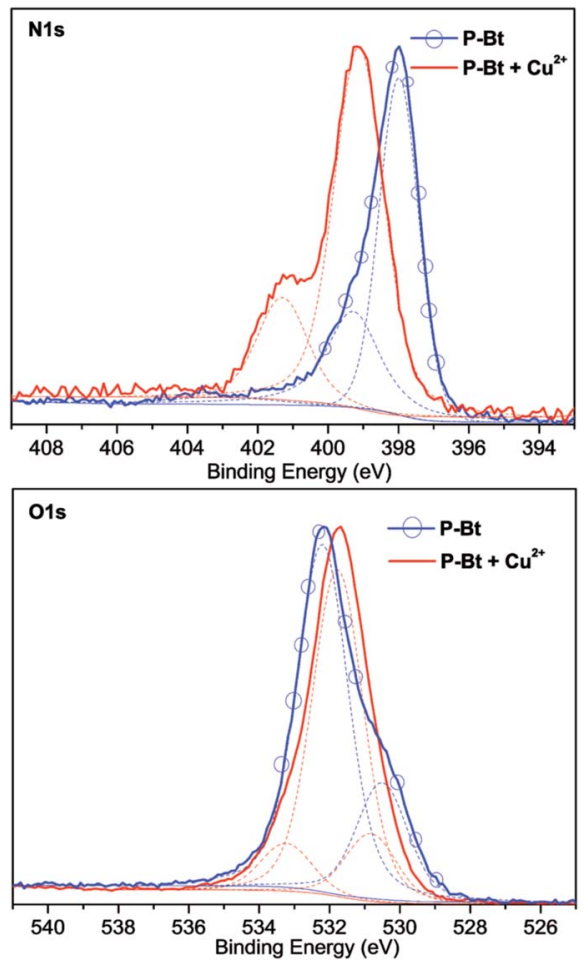

Fig. 4 XPS analysis of P-Bt and corresponding $\mathrm{Cu}^{2+}$ based MSP. The molar ratio between the unimer and $\mathrm{Cu}^{2+}$ is $(1: 1)$. the pyridine and oxazoline groups, resulting in the enhancement of the effective nuclear charge experienced by the core-electron, thereby increasing the electron binding energy. Because the binding energy of O1s electrons changed only slightly (and to a lower binding energy), a predominant coordination of metal ions through the nitrogen atoms can be expected.

UV/vis time-dependent analysis of (MSP)s. An interesting behavior for MSPs containing the $\mathrm{Fe}^{2+}$ IC was observed. All the prepared samples for the above-mentioned measurements were left without any treatment for one month in order to check the stability of MSPs formed in solution overtime. In the case of $\mathrm{Fe}^{2+}$ we observed a strong degradation of the MSP. The decomposition and loss of properties are independent of the value of $r$ (see Fig. S9b, ESI $\dagger$ ). The absorption bands around $630 \mathrm{~nm}$ assigned to MLCT totally disappeared. Additionally, the degradation of MSPs could be easily seen by the naked eye. The color of the samples changed from dark green to yellowish brown and gained the same coloration as the free unimers (see Fig. S9 in the ESI $\dagger)$. The remaining MSPs with other ICs $\left(\mathrm{Zn}^{2+}\right.$, $\left.\mathrm{Cu}^{2+}, \mathrm{Ni}^{2+}\right)$ do not degrade even after 1 month. This result for MSPs containing $\mathrm{Fe}^{2+}$ is probably caused simply by the oxidation process of the mentioned metal ions. We presume that the $\mathrm{Fe}^{2+}$-containing MSP undergoes constitutional dynamics, causing coordination of the $\mathrm{Fe}^{2+}$ IC with only one pybox chelating motif $\left(\mathrm{Fe}^{2+}\right.$ is in the chain end). In this arrangement, $\mathrm{Fe}^{2+}$ on the chain-end is probably prone to oxidation $\left(\mathrm{Fe}^{3+}\right)$. It is worth mentioning that this process is not reversible and all the attempts to restore the $\mathrm{Fe}^{2+}$ based MSP to the original state using an excess of ascorbic acid failed. This observation indicates more complex mechanisms for $\mathrm{Fe}^{2+}$ based MSP deterioration.

\section{Luminescence study}

Analysis of unimers. Fluorescence spectra have been measured in both states (solid thin film and solution) for all the unimers (P-Th, P-Bt, and P-Te). Emission spectra are presented in Fig. S10 in the ESI. $\dagger$ A mixed solvent (chloroform/methanol) $(1: 1)$ for the preparation of the samples in solution was used. Solid films were prepared by a spin coating method, using the same solvent system. The basic unimer emission characteristics $\left(\lambda_{\mathrm{F}}(\mathrm{nm})\right.$ emission maxima and $\phi_{\mathrm{F}}(\%)$ fluorescence quantum yields) are shown in Table 2 . The synthesized unimers showed a red shift of emission in solution in the following order: P-Th $>$ P-Te > P-Bt. A deviation from the dependence measured in solution was observed in the thin film, with the following order: $\mathbf{P}$-Te $>$ P-Th $>$ P-Bt. A shift of maximal fluorescence to a longer wavelength (of $50 \mathrm{~nm}$ for P-Te and $180 \mathrm{~nm}$ for P-Th) was observed. Such a large bathochromic shift in the solid state for $\mathbf{P}$-Th, compared to P-Te and P-Bt, is the result of a lowest substituent hindrance (thiophene-linker) compared to the rest of the unimers, strongly influencing molecular packing in the solid state.

MSP characterization. Titration experiments of the unimers were performed with the above-mentioned ICs. The value of $r$ was increased stepwise (see the Experimental part). The same set of solutions as used for the UV/vis study was used for this 
experiment. MSPs prepared with the $\mathrm{Zn}^{2+}$ IC exhibit a remarkable increase of fluorescence intensity ( 3 times as much, $r=1$ ). The emission spectra of MSPs containing ICs $\left(\mathrm{Fe}^{2+}, \mathrm{Cu}^{2+}, \mathrm{Ni}^{2+}\right)$ showed only fluorescence quenching. The whole appearance of the fluorescence spectra can be found in Fig. 5, including titration experiments. Both absorption and emission spectra serve as a good confirmation of MSP formation. Since only complexation with $\mathrm{Zn}^{2+}$ metal ions leads to an increase of fluorescence and $\mathrm{Zn}^{2+}$ based MSPs emit bright yellow light, the fluorescence quantum yield (FQY) measurement from this IC containing MSPs was performed (value of $r=1$ ). The results of the measurement of the FQY and emission maxima are illustrated in Table 2. Comparing the free unimers and their MSPs (further denoted as "unimer + $\mathrm{Zn}$ "), the above-mentioned characteristics for $\mathbf{P}-\mathbf{T h}+\mathbf{Z n}$ and $\mathbf{P}-\mathbf{B t}+\mathbf{Z n}$ were 2 and 3 times higher than for free P-Th and P-Bt, respectively. The solid-state emission bands for $\mathrm{Zn}$ based MSPs show a bathochromic shift in the following order: P-Th $>$ P-Te $>$ P-Bt, corresponding to the order in solution measurements. FQYs were also measured in solid thin films for $\mathrm{Zn}^{2+}$ based MSPs. The results of FQYs have a similar trend to that observed in the solution and are summarized in Table 2.

NMR titration study. In order to check the self-assembly process of the synthesized unimers into MSPs, a complexation study of the Pybox-Th ligand with the $\mathrm{Zn}^{2+}$ IC was performed. From a visual point of view, the indicated ligand resembles "half a P-Bt unimer" and is therefore a convenient molecule for comparison. The approximate character of the experiment must be taken into account. The coordination of the ICs to the one side of bidentate unimer strongly influences the second coordination site. The coordination of Pybox-Th with $\mathrm{Zn}^{2+}$ in a deuterated chloroform/methanol mixed solvent $(1: 1)$ in various $r$ ratios clearly shows that the ion coupler used coordinates two ligands. The main changes in the NMR titration spectra were detected at $r=0.5$, where the proton signals ascribed to thiophene, as well as those ascribed to oxazoline $\left(\mathrm{CH}_{2} \mathrm{O}\right)$ moieties, are shifted downfield (see Fig. S11 in the ESI $\dagger$ ). The further addition of $\mathrm{Zn}^{2+}$ has no influence on the character of the NMR spectra. The corresponding NMR titration spectra of the PyboxTh ligand correlates very well with the UV/vis spectra. NMR titration experiments with the unimers were performed using $\mathbf{P}$ Th and the $\mathrm{Zn}^{2+}$ IC. The above-mentioned MSP system was chosen due to its better solubility of the P-Th unimer among other unimers and due to the diamagnetic character of the $\mathrm{Zn}^{2+}$ based MSP, allowing NMR analysis. The measurements were performed in DMSO- $d_{6}$ using concentrations for P-Th of $0.02 \mathrm{M}$ and for $\mathrm{Zn}^{2+}$ of $0.2 \mathrm{M}$. DMSO- $d_{6}$ was chosen due to: (i) the good solubility of all the components in the system unimer, selected ion coupler and formed MSPs (as well as the supportive function of DMSO- $d_{6}$ mentioned above); (ii) no overlap with the signals ascribable to the unimer and formed MSPs. The NMR titration spectra are summarized in Fig. S12 in the ESI. $\dagger$ The free uncoordinated unimer P-Th has proton signals in both the high and low field regions of the proton scale. The changes in both regions were observed after the addition of diamagnetic IC $\left(\mathrm{Zn}^{2+}\right)$. The down-field signals ascribable to the aromatic rings (thiophene and pyridine) were shifted down from 8.08 to $8.15 \mathrm{ppm}$ for thiophene and from 8.3 to $8.35 \mathrm{ppm}$ for pyridine moiety.

Additionally, new signals close to the main signals of the aromatic moieties appeared and negligible broadening was also observed, indicating the presence of constitutional dynamics in solution. ${ }^{48}$ The second series of signals in the lower magnetic field corresponding to the oxazoline groups also shifted downfield from 4.5 to $4.6 \mathrm{ppm}$ for $\mathrm{CH}_{2} \mathrm{O}$ and from 4.06 to $4.12 \mathrm{ppm}$ for $\mathrm{CH}_{2} \mathrm{~N}$ groups. However, the main changes upon complexation are seen when $r$ is close to unity and a further addition (or increase) of $\mathrm{Zn}^{2+}$ IC concentration does not lead to shift changes in the NMR spectra. These results, together with the UV/vis study, revealed that the most stable and probably possessing the longest MSP chains are systems with $r=1$. Besides that, the formation of MSPs using the P-Bt unimer and the $\mathrm{Cu}^{2+}$ IC with $r$ $=1$ was confirmed by a MALDI-TOF study. The mass $m / z(z=2)$ corresponding to the U-IC-U-IC sequence (found for $\mathrm{C}_{60} \mathrm{Cu}_{2}$ $\mathrm{H}_{48} \mathrm{~N}_{12} \mathrm{O}_{8} \mathrm{~S}_{4}$, (658.8)), together with the peaks of different fragments with higher $\mathrm{m} / \mathrm{z}$ values, indicate the certainty of MSP formation and the presence of high molecular oligomeric sequences that were observed (see Fig. S13, ESI $\dagger$ ). Further deciphering of the MALDI-TOF spectrum is nearly impossible (also due to the presence of $\mathrm{ClO}_{4}{ }^{-}$counterions).
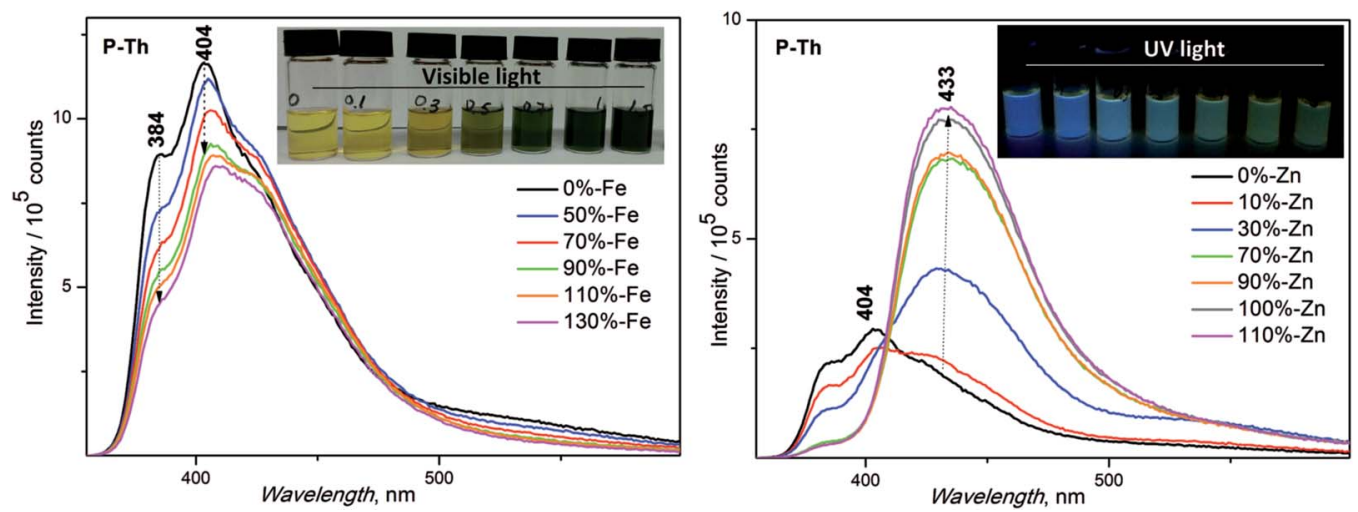

Fig. 5 Emission spectra of P-Th with increasing amounts of $\mathrm{Zn}^{2+}$ and $\mathrm{Fe}^{2+}$ metal ions. Inset: captured pictures of samples, $\mathrm{Zn}{ }^{2+}-\mathrm{UV}$ light, Fe $\mathrm{Fe}^{2+}$ visible light. 


\section{Experimental section}

\section{Materials}

Tetrabutylammonium bromide, thionyl chloride, 2-chloroethylamine hydrochloride, triethylamine, 1,3-bis(diphenylphosphino)propane nickel(II) chloride $\left[\mathrm{Ni}(\mathrm{dppp}) \mathrm{Cl}_{2}\right]$ (dpp stands for diphenylphosphino-propane), 2,5-bis(trimethylstannyl)thiophene, 5,5'-bis(trimethylstannyl)-2,2'-bithiophene, 2,5-bis(trimethylstannyl)-thieno[3,2-b]thiophene, zinc(II) perchlorate hexahydrate, iron(II) perchlorate hydrate, nickel(II) perchlorate hexahydrate, copper(II) perchlorate hexahydrate, (all from Sigma-Aldrich) and 4-hydroxypyridine-2,6-dicarboxylic (chelidamic) acid (1), were obtained from commercial sources (Sigma-Aldrich) and used without further purification.

Solvents used for the palladium catalyzed synthesis of unimers and ligands such as toluene and tetrahydrofuran (THF) were dried and distilled by standard methods and stored under argon. Toluene (Lachner) was distilled under argon from sodium/benzophenone prior to use, THF (Aldrich) was distilled from $\mathrm{LiAlH}_{4}$ before use, methanol (Aldrich), dichloromethane and chloroform (both from Lachner), were used as obtained.

\section{Measurements}

${ }^{1} \mathrm{H}$ and ${ }^{13} \mathrm{C}$ NMR spectra were recorded on Varian ${ }^{\text {UNITY INOVA }}$ 400 or Varian SYSTEM 300 instruments in $\mathrm{CDCl}_{3}, d_{6}$-DMSO, $\mathrm{CD}_{3} \mathrm{OD}$ and referenced to the solvent signal $(\delta): 7.25 \mathrm{ppm}$ $\left(\mathrm{CDCl}_{3}\right), 2.50 \mathrm{ppm}\left(d_{6}\right.$-DMSO$)$ or $3.33,4.78 \mathrm{ppm}\left(\mathrm{CD}_{3} \mathrm{OD}\right)$ for ${ }^{1} \mathrm{H}$ and $77.0 \mathrm{ppm}\left(\mathrm{CDCl}_{3}\right), 49.15 \mathrm{ppm}\left(\mathrm{CD}_{3} \mathrm{OD}\right) \mathrm{ppm}$ for ${ }^{13} \mathrm{C}$ spectra. Coupling constants, $J$ (in $\mathrm{Hz}$ ), were obtained by a first-order analysis. UV/vis spectra were recorded on a Shimadzu UV2401PC using a solvent mixture $\left(\mathrm{CHCl}_{3} / \mathrm{CH}_{3} \mathrm{OH}(1 / 1)\right)$ of the prepared compounds. Solid state samples were prepared using coating via a slow solvent evaporation technique on the surface of the quartz plate.

Photoluminescence spectra were measured on a Fluorolog 3-22 Jobin Yvon Spex instrument (Jobin Yvon Instruments S. A., Inc., USA) in $\mathrm{CHCl}_{3}+\mathrm{CH}_{3} \mathrm{OH}$ solutions using a four-window quartz cuvette $(1 \mathrm{~cm})$. The emission spectra were excited using the wavelength, $\lambda_{\mathrm{ex}}$, equal to the position of the absorption maxima of a particular compound. Quantum yields, $\phi_{\mathrm{F}}$, of photoluminescence were measured using an integration sphere Quanta- $\varphi$ F-3029 Horriba Jobin Yvon. X-ray diffraction studies were performed using Bragg-Brentano geometry on a PanAlytical X'Pert PRO MPD X-ray diffraction system equipped with a PIXcel detector using a Cu-anode $(\mathrm{Cu}-\mathrm{K} \alpha ; \lambda=1.5418 \AA)$. X-ray photoelectron spectroscopy (XPS) measurements were carried out with a K-Alpha ${ }^{+}$spectrometer (ThermoFisher Scientific, East Grinstead, UK). The samples were analyzed using a microfocused, monochromated $\mathrm{Al} \mathrm{K \alpha}$ X-ray source (400 $\mu \mathrm{m}$ spot size) at an angle of incidence of $30^{\circ}$ (measured from the surface) and an emission angle normal to the surface. The kinetic energy of the electrons was measured using a $180^{\circ}$ hemispherical energy analyzer operated in the constant analyzer energy mode (CAE) at a $50 \mathrm{eV}$ pass energy for the high resolution spectra. Data acquisition and processing were performed using Thermo Advantage software. XPS spectra were fitted with Voigt profiles obtained by convolving Lorentzian and Gaussian functions. The analyzer transmission function, Scofield sensitivity factors, and effective attenuation lengths (EALs) for photoelectrons were applied for quantification. EALs were calculated using the standard TPP-2M formalism. All the spectra were referenced to the $\mathrm{C} 1 \mathrm{~s} \mathrm{sp}^{2}$ peak at $284.2 \mathrm{eV}$. The BE scale was controlled by the well-known positions of the photoelectron $\mathrm{C}-\mathrm{C}$ and $\mathrm{C}-\mathrm{H}, \mathrm{C}-\mathrm{O}$ and $\mathrm{C}(=\mathrm{O})-\mathrm{O}$ peaks of polyethylene terephthalate and $\mathrm{Cu} 2 \mathrm{p}$, $\mathrm{Ag} 3 \mathrm{~d}$, and $\mathrm{Au} 4 \mathrm{f}$ peaks of metallic $\mathrm{Cu}, \mathrm{Ag}$ and $\mathrm{Au}$, respectively. The BE uncertainty of the reported measurements and analysis is in the range of $\pm 0.1 \mathrm{eV}$.

SEC records were obtained using a Spectra Physics Analytical HPLC pump P1000 with two SEC columns: Polymer Labs (Bristol, USA) Mixed-D and Mixed-E. The system was equipped with a Thermo UV6000 DAD detector. $0.05 \mathrm{M}$ tetrabutylammoniumhexafluoro-phosphate in $\mathrm{CHCl}_{3} /$ methanol $(1 / 1, \mathrm{v} / \mathrm{v}, \mathrm{CHRO}-$ MASOLV, RiedeldeHaen) was used as an eluent $\left(0.7 \mathrm{~mL} \mathrm{~min}^{-1}\right)$.

Molecular weights of the MSPs were measured by the following method. The raw samples were withdrawn directly from the polymerization mixture and dissolved in a $1 / 1$ chloroform/methanol mixture to a concentration of $1 \mathrm{mg}$ $\mathrm{mL}^{-1}$. Samples were mixed with a matrix solution (saturated solution of $10 \mathrm{mg} \mathrm{mL}^{-1}$ dithranol in $1 / 1$ chloroform/methanol mixture) in a ratio of $1 / 100(\mathrm{v} / \mathrm{v}) \cdot 1 \mu \mathrm{L}$ of this mixture was deposited on a polished steel MALDI target (Bruker).

Mass spectra of the polymers were measured on an UltrafleXtreme TOF instrument (Bruker), equipped with a $355 \mathrm{~nm}$ smartbeam-2 laser, capable of a pulsing frequency of $1 \mathrm{kHz}$. The mass spectrometer was operated by FlexControl 3.3 software (Bruker). The acquired spectra were processed by FlexAnalysis 3.3 software (Bruker). The ionization laser power was adjusted to just above the threshold in order to produce charged species.

\section{Synthesis of starting materials}

Starting compounds dimethyl 4-hydroxypyridine-2,6dicarboxylate (2), dimethyl 4-bromopyridine-2,6-dicarboxylate (3), 4-bromopyridine-2,6-dicarboxylic acid (4), 4-bromopyridine-2,6-dicarbonyl dichloride (5), 4-bromo- $N^{2}, N^{6}$-bis(2chloroethyl)pyridine-2,6-dicarboxamide (6) and 4-bromo-2,6bis(4,5-dihydro-2-oxazolyl)-pyridine (7) were prepared according to a modified previously reported synthetic procedure. ${ }^{49}$ For more detailed information (synthesis and spectra) see the ESI. $\uparrow$

\section{Synthesis of unimers}

2,6-Bis(oxazoline-2-yl)-4-(2-thienyl)pyridine (Pybox-Th). PyboxTh was prepared according to the known above-mentioned procedure (see the ESI $\dagger$ for further details). The process of crystallization gave a white solid powder with yield $1.15 \mathrm{~g}$ or $72 \% .{ }^{1} \mathrm{H}$ NMR (300 MHz, $\left.\mathrm{CDCl}_{3}, \mathrm{ppm}\right) \delta 8.33$ (s, 2H-pyH, $\mathrm{H}^{\mathrm{A} 3}$ ), $7.65(\mathrm{~d}, 1 \mathrm{H}-$ Th, $\mathrm{H}^{\mathrm{B} 2}$ ), 7.47 (d, 1H-Th, $\left.\mathrm{H}^{\mathrm{B} 4}\right), 8.33\left(\mathrm{t}, 1 \mathrm{H}-\mathrm{Th}, \mathrm{H}^{\mathrm{B} 3}\right), 4.55(\mathrm{t}, 4 \mathrm{H}-$ $\left.\mathrm{CH}_{2} \mathrm{~N}, \mathrm{H}^{\mathrm{C} 2}\right), 4.14\left(\mathrm{t}, 4 \mathrm{H}-\mathrm{CH}_{2} \mathrm{O}, \mathrm{H}^{\mathrm{C} 3}\right)$. Anal. calculated for $\mathrm{C}_{15} \mathrm{H}_{13} \mathrm{~N}_{3} \mathrm{O}_{2} \mathrm{~S}\left(M_{\mathrm{w}} 29935 \mathrm{~g} \mathrm{~mol}^{-1}\right), \mathrm{C}, 60.19 ; \mathrm{H}, 4.38 ; \mathrm{N}, 14.04 ; \mathrm{S}$, 10.71, found: C, 59.87; H, 4.41; N, 14.52; S, 10.45 .

2,5-Bis(2,6-bis(4,5-dihydrooxazol-2-yl)pyridin-4-yl)thiophene (P-Th). To a mixture of $\mathrm{Pd}\left(\mathrm{PPh}_{3}\right)_{2} \mathrm{Cl}_{2}(0.02 \mathrm{~g}, 0.03 \mathrm{mmol})$ and 2,5bis(trimethylstannyl)thiophene $(0.24 \mathrm{~g}, 0.58 \mathrm{mmol})$ in freshly 
distilled toluene $(10 \mathrm{~mL})$, compound 7 (0.4 g, $1.35 \mathrm{mmol})$ was added. The resulting mixture was stirred under argon at $100{ }^{\circ} \mathrm{C}$ for $24 \mathrm{~h}$. The reaction mixture was allowed to cool down and toluene was removed by a rotary evaporator. The solid residue was dissolved in a chloroform-methanol mixture $(5 \mathrm{~mL})$ and the product was precipitated by adding diethyl ether to the solution (ca. $10 \mathrm{~mL}$ ). This precipitation gave a yellow solid product which was filtered off and washed with hexane, methanol and ether. Yield: $0.45 \mathrm{~g}, 65 \%$. The formal group numbering for the NMR assignment is given in Scheme 1. ${ }^{1} \mathrm{H}$ NMR $\left(300 \mathrm{MHz}, \mathrm{CDCl}_{3}+\right.$ $\left.\mathrm{CD}_{3} \mathrm{OD}, \mathrm{ppm}\right) \delta 8.19\left(\mathrm{~s}, 4 \mathrm{H}-\mathrm{pyH}, \mathrm{H}^{\mathrm{A} 3}\right), 7.6\left(\mathrm{~s}, 2 \mathrm{H}-\mathrm{Th}, \mathrm{H}^{\mathrm{B} 3}\right), 4.43(\mathrm{t}$, $8 \mathrm{H}-\mathrm{CH}_{2} \mathrm{~N}, \mathrm{H}^{\mathrm{C} 2}$ ), $3.98\left(\mathrm{t}, 8 \mathrm{H}-\mathrm{CH}_{2} \mathrm{O}, \mathrm{H}^{\mathrm{C} 3}\right) .{ }^{13} \mathrm{C} \mathrm{NMR}(400 \mathrm{MHz}$, $\left.\mathrm{CDCl}_{3}+\mathrm{CD}_{3} \mathrm{OD}, \mathrm{ppm}\right) \delta 163.97\left(\mathrm{C}^{\mathrm{C} 1}\right), 147.71\left(\mathrm{C}^{\mathrm{A} 4}\right), 142.81\left(\mathrm{C}^{\mathrm{A} 2}\right)$, $141.96\left(\mathrm{C}^{\mathrm{B} 2}\right), 128.56\left(\mathrm{C}^{\mathrm{B} 3}\right), 121.74\left(\mathrm{C}^{\mathrm{A} 3}\right), 68.91\left(\mathrm{C}^{\mathrm{C} 3}\right), 54.95\left(\mathrm{C}^{\mathrm{C} 2}\right)$. Anal. calculated for $\mathrm{C}_{26} \mathrm{H}_{22} \mathrm{~N}_{6} \mathrm{O}_{4} \mathrm{~S}$ (MW $514.56 \mathrm{~g} \mathrm{~mol}^{-1}$ ), C, 60.69; H, 4.31; N, 16.33; O, 12.44; S, 6.23, found: C, 59.27; H, $4.41 ; \mathrm{N}, 15.82 ; \mathrm{S}, 6.02$.

5,5'-Bis(2,6-bis(4,5-dihydrooxazol-2-yl)pyridin-4-yl)-2,2'-bithiophene (P-Bt). This was prepared according to the procedure for P-Th using $\mathrm{Pd}\left(\mathrm{PPh}_{3}\right)_{2} \mathrm{Cl}_{2}(0.017 \mathrm{~g}, 0.025 \mathrm{mmol}), 5,5^{\prime}$-bis(trimethylstannyl)-2,2'-bithiophene $(0.22 \mathrm{~g}, 0.44 \mathrm{mmol})$ and compound 7 ( $0.3 \mathrm{~g}, 1 \mathrm{mmol})$ in dry toluene $(10 \mathrm{~mL})$. Yield: $0.4 \mathrm{~g}$, $66 \%$. The formal group numbering for the NMR assignment is given in Scheme 1. ${ }^{1} \mathrm{H}$ NMR (300 $\mathrm{MHz}, \mathrm{CDCl}_{3}+\mathrm{CD}_{3} \mathrm{OD}, \mathrm{ppm}$ ) $\delta 8.07$ (s, 4H-pyH, $\mathrm{H}^{\mathrm{A} 3}$ ), $7.43\left(\mathrm{~d}, 2 \mathrm{H}-\mathrm{Th}, \mathrm{H}^{\mathrm{B} 3}\right), 7.12(\mathrm{~d}, 2 \mathrm{H}-\mathrm{Th}$, $\left.\mathrm{H}^{\mathrm{B} 4}\right), 4.36\left(\mathrm{t}, 8 \mathrm{H}-\mathrm{CH}_{2} \mathrm{~N}, \mathrm{H}^{\mathrm{C} 2}\right), 3.9\left(\mathrm{t}, 8 \mathrm{H}-\mathrm{CH}_{2} \mathrm{O}, \mathrm{H}^{\mathrm{C} 4}\right) .{ }^{13} \mathrm{C} \mathrm{NMR}$ $\left(400 \mathrm{MHz}, \mathrm{CDCl}_{3}+\mathrm{CD}_{3} \mathrm{OD}, \mathrm{ppm}\right) \delta 164.02\left(\mathrm{C}^{\mathrm{C} 1}\right), 147.48\left(\mathrm{C}^{\mathrm{A} 4}\right)$, $142.78\left(\mathrm{C}^{\mathrm{A} 2}\right), 139.67\left(\mathrm{C}^{\mathrm{B} 5}\right), 138.96\left(\mathrm{C}^{\mathrm{B} 2}\right), 127.99\left(\mathrm{C}^{\mathrm{B} 4}\right), 126.08$ $\left(\mathrm{C}^{\mathrm{B} 3}\right), 121.4\left(\mathrm{C}^{\mathrm{A} 3}\right), 68.84\left(\mathrm{C}^{\mathrm{C} 3}\right), 54.91\left(\mathrm{C}^{\mathrm{C} 2}\right)$. Anal. calculated for $\mathrm{C}_{30} \mathrm{H}_{24} \mathrm{~N}_{6} \mathrm{O}_{4} \mathrm{~S}_{2}$ (MW 596.68 $\mathrm{g} \mathrm{mol}^{-1}$ ), C, 60.39; H, 4.05; N, 14.08; O, 10.73; S, 10.75, found: C, 59.29; H, 4.04; N, 13.99; S, 10.74.

2,5-Bis(2,6-bis(4,5-dihydrooxazol-2-yl)pyridin-4-yl)thieno $[\mathbf{3}, \mathbf{2}-\boldsymbol{b}]$ thiophene (P-Te). Compound P-Te was prepared according to the procedure for P-Th using $\mathrm{Pd}\left(\mathrm{PPh}_{3}\right)_{2} \mathrm{Cl}_{2}(0.017 \mathrm{~g}$, $0.025 \mathrm{mmol}$ ), 2,5-bis(trimethylstannyl)-thieno[3,2-b]thiophene $(0.21 \mathrm{~g}, 0.46 \mathrm{mmol})$ and compound $7(0.3 \mathrm{~g}, 1 \mathrm{mmol})$ in dry toluene $(10 \mathrm{~mL})$. Yield: $0.34 \mathrm{~g}, 59 \%$. The formal group numbering for NMR assignment is given in Scheme 1. ${ }^{1} \mathrm{H}$ NMR $\left(300 \mathrm{MHz}, \mathrm{CDCl}_{3}+\mathrm{CD}_{3} \mathrm{OD}, \mathrm{ppm}\right) \delta 8.15\left(\mathrm{~s}, 4 \mathrm{H}-\mathrm{pyH}, \mathrm{H}^{\mathrm{A} 3}\right), 7.75(\mathrm{~s}$, $\left.2 \mathrm{H}-\mathrm{Te}, \mathrm{H}^{\mathrm{B} 3}\right), 4.4\left(\mathrm{t}, 8 \mathrm{H}-\mathrm{CH}_{2} \mathrm{~N}, \mathrm{H}^{\mathrm{C} 2}\right), 3.94\left(\mathrm{t}, 8 \mathrm{H}-\mathrm{CH}_{2} \mathrm{O}, \mathrm{H}^{\mathrm{C} 3}\right) \cdot{ }^{13} \mathrm{C}$ NMR (400 MHz, $\left.\mathrm{CDCl}_{3}+\mathrm{CD}_{3} \mathrm{OD}, \mathrm{ppm}\right) \delta 164.16\left(\mathrm{C}^{\mathrm{C} 1}\right), 147.43$ $\left(\mathrm{C}^{\mathrm{A} 4}\right), 143.52\left(\mathrm{C}^{\mathrm{A} 2}\right), 142.86\left(\mathrm{C}^{\mathrm{B} 4}\right), 141.76\left(\mathrm{C}^{\mathrm{B} 2}\right), 121.49\left(\mathrm{C}^{\mathrm{B} 3}\right)$, $119.52\left(\mathrm{C}^{\mathrm{A} 3}\right), 68.72\left(\mathrm{C}^{\mathrm{C} 3}\right), 54.59\left(\mathrm{C}^{\mathrm{C} 2}\right)$. Anal. calculated for $\mathrm{C}_{28} \mathrm{H}_{22} \mathrm{~N}_{6} \mathrm{O}_{4} \mathrm{~S}_{2}$ (MW 570.64 $\mathrm{g} \mathrm{mol}^{-1}$ ), C, 58.94; H, 3.89; N, 14.73; O, 11.21; S, 11.24, found: C,58.17; H, 3.96; N, 13.98; S, 10.76.

\section{Preparation of metallo-supramolecular polymers}

A set of solutions of the unimers P-Th, P-Bt and P-Te at both a constant concentration $\left(2 \times 10^{-4} \mathrm{M}\right)$ and volume $(2 \mathrm{~mL})$ was prepared in a chloroform/methanol mixture ( $1 / 1$ by vol). Additionally, the solutions of $\mathrm{Fe}^{2+}, \mathrm{Zn}^{2+}, \mathrm{Ni}^{2+}$, and $\mathrm{Cu}^{2+}$ perchlorate hydrates $\left(2 \times 10^{-2} \mathrm{M}\right)$ in the same solvent mixture were added into the solution of the particular unimer in ratios $r$ from $0.1 \mathrm{eq}$. to 2.5 eq. The optical properties (UV/vis, photoluminescence) of all the solutions were measured after 24 hours in order to get an inner equilibrium of the solution for signal measurement.

\section{NMR titration study}

NMR titration experiments of the MSPs were performed in DMSO- $d_{6}$ solvent. The mixture of deuterated solvents, chloroform/methanol (1/1 by volume), applicable for all the other spectroscopic studies in solution in the current work was not used due to the insolubility of the unimer to the concentration $\left(2 \times 10^{-2} \mathrm{M}\right)$ required for NMR study and a sufficient resolution of the NMR spectrum for interpretation. Therefore, DMSO- $d_{6}$ solvent was used only for NMR titration of the P-Th unimer with the $\mathrm{Zn}^{2+}$ IC as a suitable solvent allowing the preparation of solutions at the desired concentrations for NMR analysis. The stock solution of P-Th $\left(2 \times 10^{-2} \mathrm{M}\right)$ was prepared in the mentioned solvent and divided into 8 portions equal to $0.5 \mathrm{~mL}$ each. Simultaneously, $\mathrm{Zn}\left(\mathrm{ClO}_{4}\right)_{2} \times 6 \mathrm{H}_{2} \mathrm{O}$ at a concentration of $0.2 \mathrm{M}$ in deuterated DMSO was prepared and added to the P-Th solutions stepwise in the following $r$ : $0,0.25,0.5,0.75$, $1,1.25,1.5,2$ eq. The prepared samples were left for $24 \mathrm{~h}$ to achieve inner equilibrium before NMR measurements.

NMR experiments for the Pybox-Th ligand were performed in the same way as for P-Th, but using a deuterated mixture of chloroform and methanol $(1: 1)$ as a solvent.

\section{End-capping experiment of MSPs based on P-Bt and $\mathrm{Zn}^{2+}$}

Stock solutions of P-Bt (SS1) and Pybox-Th (SS2) (0.02 M for both) in the mixture of solvents (methanol and chloroform, $1: 1)$ were prepared. The structure of Pybox-Th is outlined in Scheme 1 . An aliquot of $20 \mu \mathrm{L}$ of each solution (SS1 and SS2) was taken and dissolved to $2 \mathrm{~mL}$. For convenience, dissolved P-Bt is called SA solution and Pybox-Th is called SB solution. The $\mathrm{UV} / \mathrm{vis}$ spectra of the prepared samples were measured. The solution of $\mathrm{Zn}\left(\mathrm{ClO}_{4}\right)_{2} \times 6 \mathrm{H}_{2} \mathrm{O}(0.02 \mathrm{M})$ was prepared and used as the IC during the synthesis of MSPs by the following method: to the SA solution was added $\mathrm{Zn}^{2+}$ metal ions $(20 \mu \mathrm{L})$ and the resulting mixture, referred as $\mathrm{C}$ was stirred for $1 \mathrm{~h}$ and after that was left for $24 \mathrm{~h}$ in order to have the inner equilibrium in solution mentioned above. The UV/vis spectrum of the solution was measured in order to check the formation of the metallosupramolecular polymer. Subsequently, $20 \mu \mathrm{L}$ of Pybox-Th (SS2) was added to the SC solution. After that, the resulting solution was stirred for $1 \mathrm{~h}$ and subjected to UV/vis measurement. Additionally, $10 \mu \mathrm{L}$ of $\mathrm{Zn}^{2+}$ ICs were added to the SB solution and the absorption spectrum was recorded.

\section{Conclusions}

In summary, the novel ditopic pybox based unimers, using cheap and available chelidamic acid as a precursor, have been successfully prepared and characterized. Upon treatment of the synthesized unimers with ion couplers, $\mathrm{Fe}^{2+}, \mathrm{Zn}^{2+}, \mathrm{Ni}^{2+}, \mathrm{Cu}^{2+}$, the metallo-supramolecular polymers were formed. Formation of the MSPs was investigated by UV/vis, fluorescence and NMR spectroscopies. The appearance of new absorption bands and isosbestic points confirmed the formation of the abovementioned species. The incorporation of different metal ions into the polymer chain resulted in a difference in the optical properties of the MSPs formed. The highest shift of maximal 
absorption to lower energies, compared to free unimers, was observed for complexation/assembling with the $\mathrm{Cu}^{2+}$ IC. Adversely, the lowest shift of the maximal absorption position to lower energies was detected for the $\mathrm{Fe}^{2+}$ ion coupler for all the unimers in the studied group, but in this case new bands around $600 \mathrm{~nm}$, ascribable to the metal to ligand charge transfer transition (MLCT), were observed. Complexation of unimers with $\mathrm{Zn}^{2+}$ leads to a significant increase in fluorescence intensity, contrary to all the other metals, which showed fluorescence quenching. However, the presence of uncoordinated metal centers in the metallo-supramolecular polymers makes them capable of interacting with certain tridentate monotopic ligands. This confirms the dynamic character of the prepared MSPs (constitutional dynamics between formed MSP chains and free unimer in solution).

\section{Acknowledgements}

The authors are grateful to the Czech Science Foundation (project 15-22305S) and the COST Action CM1302 (SIPS) European Network on Smart Inorganic Polymers and the Grant Agency of Charles University (project number 876213 and 796713) for financial support.

\section{References}

1 J.-M. Lehn, Supramol. Chem.: Concepts and Perspectives, $\mathrm{VCH}$, Weinheim, New York, 1995, vol. 8, pp. 89-138.

2 J. L. Atwood, J. E. D. Davies, D. D. MacNicol, F. Vögtle and J.-M. Lehn, Compr. Supramol. Chem., Pergamon, Oxford, 1996, vol. 6, pp. 643-690.

3 J.-M. Lehn, Makromol. Chem., Macromol. Symp., 1993, 69, 117.

4 J.-M. Lehn, Prog. Polym. Sci., 2005, 30, 814-831.

5 J. Zhang, S. M. Chen and X. H. Bu, Dalton Trans., 2010, 24872489.

6 X. Zhao, D. Sun, S. Yuan, S. Feng, R. Cao, D. Yuan, S. Wang, J. Dou and D. Sun, Inorg. Chem., 2012, 51, 10350-10355.

7 Z. Z. Lu, R. Zhang, Y. Z. Li, Z. J. Guo and H. G. Zheng, J. Am. Chem. Soc., 2011, 133, 4172-4174.

8 M. Cibian, S. Langis-Barsetti, F. G. D. Mendonça, S. Touaibia, S. Derossi, D. Spasyuk and G. S. Hanan, Eur. J. Inorg. Chem., 2015, 1, 73-82.

9 V. A. Friese and D. G. Kurth, Coord. Chem. Rev., 2008, 252, 199-211.

10 M. Chiper, R. Hoogenboom and U. S. Schubert, Macromol. Rapid Commun., 2009, 30, 565-578.

11 M. Burnworth, L. M. Tang, J. R. Kumpfer, A. J. Duncan, F. L. Beyer, G. L. Fiore, S. J. Rowan and C. Weder, Nature, 2011, 472, 334-338.

12 J. Yuan, X. Fang, L. Zhang, G. Hong, Y. Lin, Q. Zheng, Y. Xu, Y. Ruan, W. Weng, H. Xia and G. Chen, J. Mater. Chem., 2012, 22, 11515-11522.

13 J. R. Kumpfer and S. J. Rowan, J. Am. Chem. Soc., 2011, 133, 12866-12874.

14 M. H. Demirel, S. Köytepe, A. Gültek and T. Seçkin, J. Polym. Res., 2014, 21, 345-355.
15 J. Brassinne, J.-P. Bourgeois, C.-A. Fustin and J.-F. Gohy, Soft Matter, 2014, 10, 3086-3092.

16 J. R. Kumpfer, J. Jina and S. J. Rowan, J. Mater. Chem., 2010, 20, 145-151.

17 P. R. Andres and U. S. Schubert, Adv. Mater., 2004, 16, 10431068.

18 F. S. Han, M. Higuchi, Y. Akasaka, Y. Otsuka and D. G. Kurth, Thin Solid Films, 2008, 516, 2469-2473.

19 A. Maier, K. Cheng, J. Savych and B. Tieke, ACS Appl. Mater. Interfaces, 2011, 3, 2710-2718.

20 Y. Li, T. Ren and W.-J. Dong, J. Photochem. Photobiol., A, 2013, 251, 1-9.

21 R. Dong, Y. Zhou, X. Huang, X. Zhu, Y. Lu and J. Shen, Adv. Mater., 2014, 27, 498-526.

22 P. Štenclová, K. Šichová, I. Šloufová, J. Zedník, J. Vohlídal and J. Svoboda, Dalton Trans., 2016, 45, 1208-1224.

23 J. Svoboda, P. Štenclová, F. Uhlík, J. Zedník and J. Vohlídal, Tetrahedron, 2011, 67, 75-79.

24 T. Vitvarova, J. Zednik, M. Blaha, J. Vohlidal and J. Svoboda, Eur. J. Inorg. Chem., 2012, 2012, 3866-3874.

25 I. Šloufová, B. Vlčková, M. Procházka, J. Svoboda and J. Vohlídal, J. Raman Spectrosc., 2014, 45, 338-348.

26 P. Bláhová, J. Zedník, I. Šloufová, J. Vohlídal and J. Svoboda, Soft Mater., 2014, 12, 214-229.

27 D. Rais, M. Menšík, P. Štenclová-Bláhová, J. Svoboda, J. Vohlídal and J. Pfleger, J. Phys. Chem. A, 2015, 24, 62036214.

28 N. B. Shustova, A. F. Cozzolino, S. Reineke, M. Baldo and M. Dincă, J. Am. Chem. Soc., 2013, 135, 1332613329.

29 W. H. Zhang, S. W. Chien and T. S. A. Hora, Coord. Chem. Rev., 2011, 255, 1991-2024.

30 R. Custelcean, J. Bosano, P. V. Bonnesen, V. Kertesz and B. P. Hay, Angew. Chem., Int. Ed., 2009, 48, 4025-4029.

31 S. Singh, J. Chaturvedi and S. Bhattacharya, Dalton Trans., 2012, 41, 424-431.

32 E. Menéndez-Pedregal, M. Vaquero, E. Lastra, P. Gamasa and A. Pizzano, Chem.-Eur. J., 2015, 21, 549-553.

33 C. Friebe, A. Wild, J. Perelaer and U. S. Schubert, Macromol. Rapid Commun., 2012, 33, 503-509.

34 A. Duerrbeck, S. Gorelik, J. Hobley, J. Wu, A. Hor and N. Long, Chem. Commun., 2015, 51, 8656-8659.

35 B. M. Paterson and P. S. Donnelly, Chem. Soc. Rev., 2011, 40, 3005-3018.

36 L. Alibabaei, M. Wang, R. Giovannetti, J. Teuscher, D. D. Censo, J.-E. Moser, P. Comte, F. Pucciarelli, S. M. Zakeeruddin and M. Gratzel, Energy Environ. Sci., 2010, 3, 956-961.

37 S. N. MacMillan, H. W. Hill and J. C. Peters, Chem. Sci., 2014, 5, 590-597.

38 T. M. Porter, G. B. Hall, T. L. Groy and R. J. Trovitch, Dalton Trans., 2013, 42, 14689-14692.

39 F. Czerny, P. Döhlert, M. Weidauer, E. Irran and S. Enthaler, Inorg. Chim. Acta, 2015, 425, 118-123.

40 J. D. Nobbs, A. K. Tomov, R. Cariou, V. C. Gibson, A. J. P. White and G. J. P. Britovsek, Dalton Trans., 2012, 41, 5949-5964. 
41 J. Jankowska, J. Paradowska, B. Rakiel and J. Mlynarski, J. Org. Chem., 2007, 72, 2228-2231.

42 P. J. Brown, D. S. Thomas, A. Köhler, J. S. Wilson, J.-S. Kim, C. M. Ramsdale, H. Sirringhaus and R. H. Friend, Phys. Rev. B: Condens. Matter Mater. Phys., 2003, 67, 064203.

43 J. K. Stille, Angew. Chem., Int. Ed. Engl., 1986, 25, 508-524.

44 T. Suzuki, T. Sato, J. Zhang, M. Kanao, M. Higuchi and H. Maki, J. Mater. Chem. C, 2016, 4, 1594-1598.

45 J. Zhang, C.-Y. Hsu and M. Higuchi, J. Photopolym. Sci. Technol., 2014, 27, 297-300.
46 P. Štenclová-Bláhová, J. Svoboda, I. Šloufová and J. Vohlídal, Phys. Chem. Chem. Phys., 2015, 17, 13743-13756.

47 A. Bremer, U. Müllich, A. Geist and P. J. Panak, New J. Chem., 2015, 39, 1330-1338.

48 T. Vermonden, W. M. de Vos, A. T. M. Marcelis and E. J. R. Sudholter, Eur. J. Inorg. Chem., 2004, 14, 2847-2852.

49 A. De Bettencourt-Dias, S. Viswanathan and A. Rollett, J. Am. Chem. Soc., 2007, 129, 15436-15437. 